\title{
Slipped capital femoral epiphysis in an ambulant patient with spastic cerebral palsy. A long-term evolution
}

\section{Epifisiolisis proximal femoral en un paciente deambulante con parálisis cerebral espástica. Evolución a largo plazo}

https://doi.org/10.23938/ASSN.0864

S. García-Mata, A.F. D’Arrigo Azarelli, J.N. Albiñana-Cunningham

\begin{abstract}
We report the case of a boy aged 13 years and 9 months, with predominantly right-sided spastic tetraparesis, who could walk with assistance, GMFCS III, phenotype consistent with adiposogenital syndrome. He presented a 4-week history of left-sided limp without pain, radiologically classified as a stable, chronic slipped capital femoral epiphysis (SCFE) with mild slippage $\left(<30^{\circ}\right)$ on the Southwick classification.

In situ fixation of the hip was performed using a full-headed screw, followed by six weeks of rest. Twelve years since the intervention, the patient remains asymptomatic with no clinical or radiological changes.

SCFE in patients with cerebral palsy, while highly unusual, is possible. A high level of suspicion is required for diagnosing it. We would suggest ruling out the appearance of SCFE during surveillance screening of patients with cerebral palsy, $\geq 10$ years-old, particularly in obese individuals with or without adiposogenital phenotype and limited ability to communicate verbally.
\end{abstract}

Keywords. Slipped capital femoral epiphysis (SCFE). Cerebral palsy. In situ fixation.

\section{RESUMEN}

Se presenta el caso de un paciente varón de 13 años y 9 meses de edad, afecto de tetraparesia espástica de predomino derecho, con capacidad de deambulación con ayuda, GMFCS III y fenotipo de syndrome adiposogenital. Mostraba cojera de cadera izquierda de cuatro semanas de evolución y sin dolor, clinica y radiológicamente clasificada de epifisiolisis proximal femoral (SCFE) izquierda, estable y crónica, con deslizamiento medio $\left(<30^{\circ}\right)$ en la clasificación de Southwick.

Se realizó tratamiento quirúrgico mediante fijación in situ con tornillo de rosca completa, y seis semanas de descarga. Doce años después de la intervención el paciente permanece asintomático, sin cambios clínicos o radiológicos.

SCFE en pacientes afectos de parálisis cerebral infantil (PCI), aunque muy inusual, es posible. Se precisa un alto nivel de sospecha para diagnosticarlo. La aparición de SCFE debe descartarse en el despistaje habitual de las caderas de los pacientes con $\mathrm{PCI} \geq 10$ años, particularmente en pacientes obesos con/sin fenotipo adiposogenital y capacidad limitada de comunicase verbalmente.

Palabras clave. Epifisiolisis proximal femoral. Parálisis cerebral. Fijación in situ.
Pediatric Orthopaedic Section. Department of Traumatology and Orthopaedic Surgery. Complejo Hospitalario de Navarra. Pamplona.

Received: March 5, 2020

Revised: April 20, 2020

Accepted: April 28, 2020

\section{Corresponding author:}

Serafín García-Mata

Pediatric Orthopaedic Section

Trauma and Orthopaedic Department

Complejo Hospitalario de Navarra

$\mathrm{C} /$ Irunlarrea, 3

31008 Pamplona, Spain

E-mail: sgarcima@cfnavarra.es 


\section{INTRODUCTION}

Slipped capital femoral epiphysis (SCFE) is defined as a non-traumatic separation and slippage of the proximal femoral epiphysis, which usually occurs at the peak of pubertal growth. SCFE is well known to be a generalized metabolic disorder of puberty that results from a series of pubertal mishaps with a multifactorial basis. It is ordinarily caused by a relative imbalance of hormones, coupled with biomechanical events ${ }^{1}$. Typical SCFE that occurs in puberty must be differentiated from the atypical form, which may be associated with endocrine disorders or treatments of these diseases (growth hormone, chemotherapy, etc.) $)^{2}$. Typical SCFE occurs in male patients with increased weight and height, who have probably experienced accelerated speed of growth before slippage of the epiphysis.

Cerebral palsy (CP) is a wide term used to define a group of permanent neurological disorders that cause limitations and affect body posture and movements. Motor disorders are more common in childhood, and affect around 1 in 1,000 live newborns ${ }^{1}$. $\mathrm{CP}$ is attributed to a non-progressive lesion of the immature nervous system, and the most commonly observed movement disorder is spasticity. Patients are classified by the Gross Motor Function Classification System (GMFCS), according to their deambulation skills as ambulant (level I, II, III) and non-ambulant (level IV,V). Cognitive and communication problems are also common ${ }^{1}$. Hip surveillance is more often monitored before puberty in GMFCS level IV and V, in order to rule out spastic hip dysplasia. Other types of growing hip disorders are less common and therefore, they are not routinely evaluated. We report the first case of SCFE in an ambulant patient with $\mathrm{CP}$ with long-term follow-up. A high level of suspicion is required for the diagnosis of SCFE in patients with CP. The objective of the paper is to remind that this association, while highly unusual, is possible and shows the good long-term result after surgery.

\section{CASE REPORT}

Our patient was a boy, 13 years and 9 months old, who attended a specialized day center for severe psychomotor delay. At birth, he presented fetal distress and respiratory distress syndrome with subependymal and intraventricular hemorrhage causing multicystic encephalopathy with hydrocephalus treated with a ventriculoperitoneal shunt, left hemisphere atrophy with areas of residual porencephaly, and periventricular leukomalacia. As a result of these events, the boy developed predominantly right-sided spastic tetraparesis, walking with assistance, GMFCS III. He attended the clinic due to a four-week history of left-sided limp (since his mother had realized), apparently without pain, but that may have been due to the patient's difficulties in communicating and expressing himself.

Written informed consent was obtained from the subject's guardian (mother).

Physical examination revealed popliteal angle $-30^{\circ}$, left hindfoot $10^{\circ}$, right $15^{\circ}$, Thomas sign (+) $10^{\circ}$ bilateral, left lumbar hump. He was previously able to walk 100 meters with assistance on the arm of a family member, and 30 meters without support. He was obese, with a BMI of 29.75 (weight $80 \mathrm{~kg}$, height $164 \mathrm{~cm}$ ). When walking, he supported his weight preferentially on his left leg. His phenotype was consistent with adiposogenital syndrome; general clinical laboratory tests were normal, with age-appropriate levels of testosterone, estrogens, thyroid hormones, calcium, phosphorus, and vitamin D. Endocrine disease was ruled out by the pediatric endocrinology department.

Clinical findings included greater right-sided spasticity, with $-20^{\circ}$ abduction and $-30^{\circ}$ internal rotation of the left hip. Radiology (Fig. 1) showed SCFE on the left hip classified as stable and chronic, with mild slippage $\left(<30^{\circ}\right)$ on the Southwick classification, bilateral coxa valga, physeal posterior slope $18^{\circ}$, Risser 1 , open major and minor trochanter, open triradiate cartilage, modified Oxford score 19, classified as stable acuteon-chronic slipped capital femoral epiphysis.

In situ fixation of the left hip was performed with a full-threaded screw (Fig. 2A). After 6 weeks of rest and physiotherapy, full weight-bearing exercises began with the assistance of a walker. Three months after the intervention, the patient's gait was similar to before, still requiring assistance. He presented bilateral external rotation of $75^{\circ}$, and internal rotation of $35^{\circ}$, and also symmetrical abduction of $50^{\circ}$. Radiological study at six months depicted normality of the hip (Fig. 2B). Two years later (Risser 4), the patient was walking independently with the 


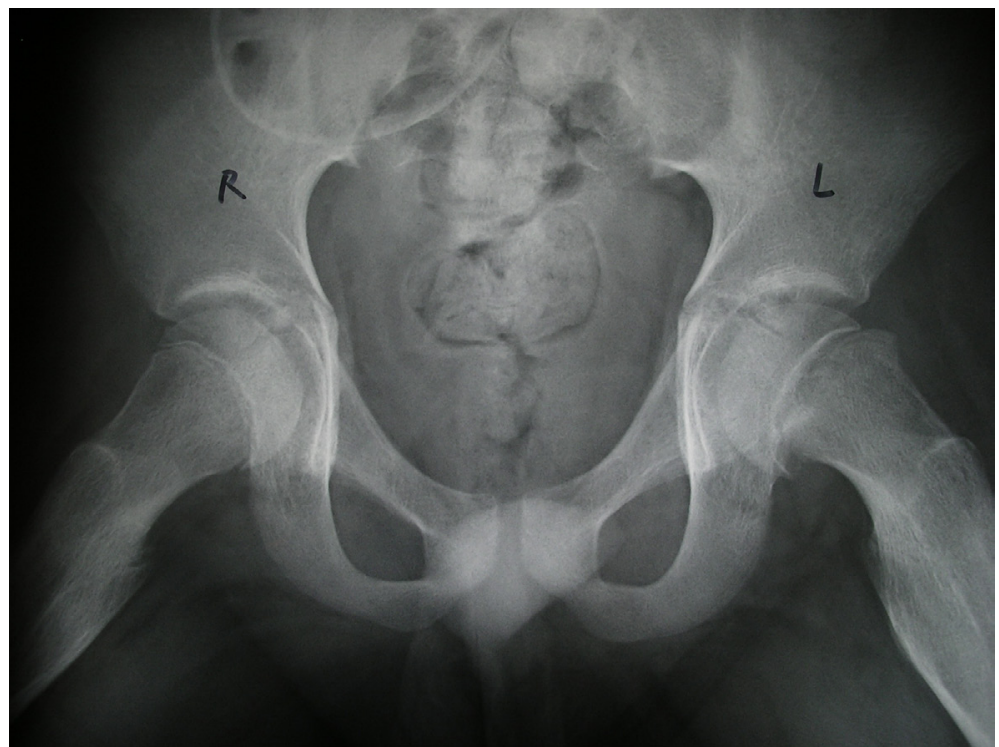

Figure 1. X-ray showing SCFE of the left hip, stable and chronic, with mild slippage. Triradiate physeal cartilage is still open.
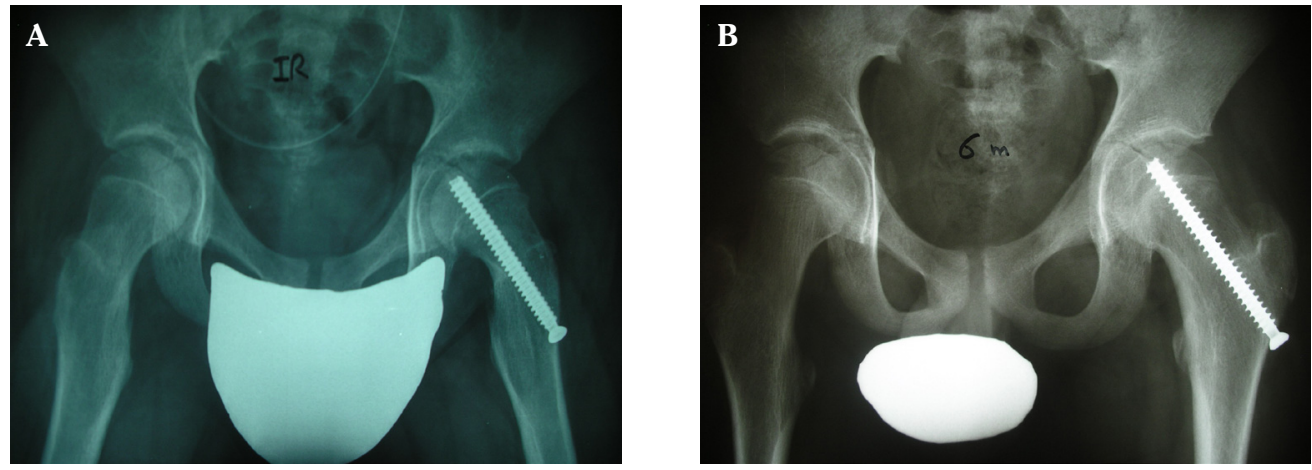

Figure 2. X-ray. A. After surgery, in situ fixation, depicting good position of the screw. Five threads in the epiphysis maintaining the stability can be observed. B. Six months later, complete reduction of the SCFE with partial closure of the proximal femoral physis, but open pelvic triradiate physis.

assistance of the arm of another person or with the walker for a distance of $400 \mathrm{~m}$, good trunk balance, asymptomatic.

Five years after the intervention, he was walking independently, Risser 5 and body mass index 24.8 (weight $71 \mathrm{~kg}$, height $169 \mathrm{~cm}$ ). Twelve years after the intervention ( 25 year-old), with full skeletal maturity, the patient remains asymptomatic with no clinical or radiological changes (Fig. 3). Removal of the screw was rejected by the family.

\section{DISCUSSION}

SCFE is an exceptional finding in patients with CP. Only three cases have been described, all in non-ambulant patients. The first, a 14-year-old girl (GMFCS V), did not receive surgical treatment, as she had physeal closing and the slippage did not progress $^{3}$. In the second, an 11-year-old girl 


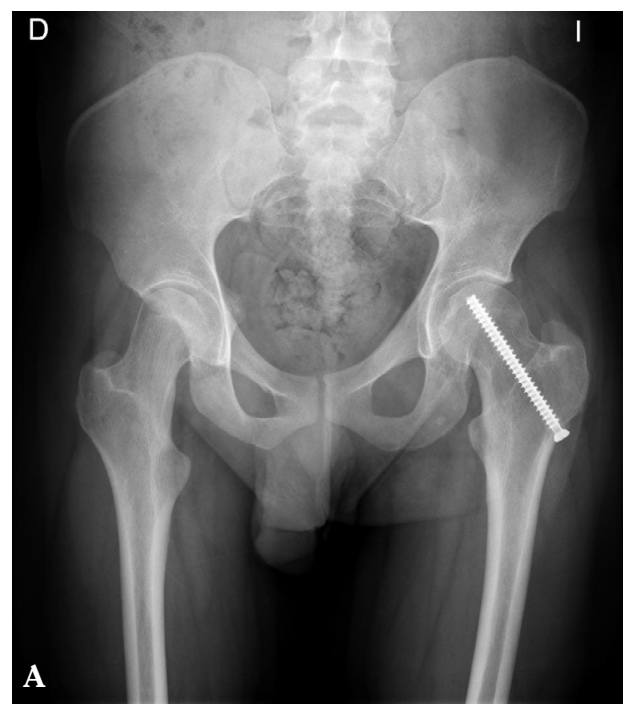

Figure 3. X-ray. A. Anteroposterior view illustrates a perfect femoral head at the age of 25 . B. Axial view depicting the growth plate fusion and good femoral head; sphericity.

(GMFCS IV), in situ fixation was performed with two cannulated screws ${ }^{4}$. The third, a 15-year-old boy (GMFCS IV-V, not clearly stated in the paper) was reported after a seizure ${ }^{5}$ with in situ fixation with one screw. Our case is the first description of atypical SCFE in an ambulant spastic CP patient without traumatic event. SCFEs can be typical (idiopathic and the most frequent) or atypical. The latter are in one of the four groups by etiology: endocrine disorder-associated SCFEs, metabolic disorders such as renal osteodystrophy, chemotherapy-associated ${ }^{4}$, and radiation therapy-associated. In absence of radiation and/or chemotherapy, atypical SCFE is associated with two types of etiological factors: endocrine and mechanical ${ }^{6}$.

Regarding endocrine factors, the socalled adioposogenital syndrome has been considered for some time as a disorder associated with SCFE but generally without hormonal or endocrine changes. As expected, we found no hormonal changes in our patient, although he did present the typical adiposogenital phenotype that would suggest the involvement of endocrine factors.

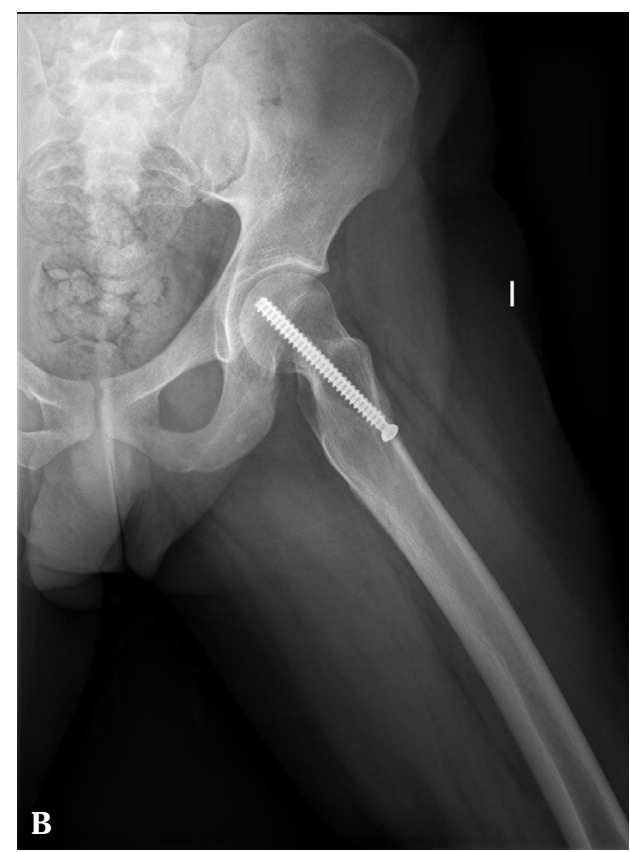

Different mechanical factors can be addressed:

- Absolute or relative retroversion of the neck of the femur and the change in the slope of the physis relative to the diaphysis and femoral neck. A reduced femoral anteversion angle is known to be specifically associated with the development of SCFE?

- Thinning of the perichondrial ring complex that occurs during the skeletal maturation of adolescents weakens the proximal femoral physis, and makes it more sensitive to the shear stress that finally causes physeal slippage ${ }^{8,9}$. This is consistent with the Risser stage 1 of bone maturation observed at the time of the patient's lesion.

- Another mechanical factor, not previously published, could be the mechanical stress caused by spasticity in an ambulant patient. Since the previously published cases $^{3-5}$ were not ambulant, this may suggest that spasticity is a mechanical stress factor just as important as weight-bear- 
ing in some patients. Both factors coincided in our patient: due to the greater right-sided spasticity the mechanical stress from walking was greater in the affected left side (with spasticity in a minor degree). It is accepted that risk factors for posterior slippage of the femoral head include external rotating forces, produced by the external rotation muscles, which occur in a sitting position ${ }^{10}$, caused by the increase in the physeal posterior slope ${ }^{11}$. In an overweight child, the combination of retroversion and the varus load on the hip is enough to increase physeal strains, causing epiphyseal slip ${ }^{12}$. The forces acting on the hip are three times greater in spastic patients, even non-ambulant, than in normal individuals ${ }^{9}$. Our patient had spasticity (increasing the stress on the femoral head) and typical signs of SCFE (femoral retroversion, obesity, and ability to walk), in addition to the risk factors described in spastic patients (coxa valga and greater shear force due to complete coverage by the acetabulum $)^{4}$.

These factors might have played a decisive role, particularly since the patient presented the other predisposing factors mentioned above. Thus, obesity, increased forces on the proximal femoral epiphysis due to spasticity, increased load on the dominant limb, increased physeal stress due to increased femoral retroversion, and weakening of the physis in adolescence are the mechanical factors that explain how SCFE may have occurred in our patient.

SCFE is generally treated surgically. In situ fixation, as performed in our patient, is the usual method in the case of stable $\mathrm{SCFE}^{13}$, particularly if the patient is still growing (case reported by Quick and Williamson ${ }^{4}$ ) and able to walk (present case). Nhamoucha et $\mathrm{al}^{5}$ also performed in situ fixation in an unstable SCFE but they did not report the clinical or radiological result except the post-op x-ray. In the case of Kardashian and Strongwater ${ }^{3}$, the patient progressed satisfactorily because she was non-ambulant, her physis were almost closed, and probably because the lesion may have been chronic.

Chronic musculoskeletal lesions with no reported pain (patellar stress fracture) have been described in CP patients ${ }^{14}$. Similarly, SCFE may go unnoticed in CP patients if they are non-ambulant (as in the cases described), as no limping can be seen, and their capacity for communicating pain and emotions is limited. The three previously published cases were non-ambulant and incapable of communicating verbally, so it was impossible to confirm chronicity, unlike our patient who showed clear worsening of his gait with increased limp compared to his normal status, although he did not appear to be in pain. Mean time to diagnosis of SCFE in the general population is 17 weeks (range: $0-169)^{15}$. This delay may increase in CP patients who have difficulties communicating verbally and producing language, since their speech may be barely intelligible, making it difficult for them to interact with their parents/caregivers, so many problems remain undetected.

In spastic patients, hip surveillance is recommended to screen for hip dislocation in GMFCS I, II and III patients up to 10 years of age. We believe that families and providers of care must be educated regarding hip problems in patients with $\mathrm{CP}$, and the possibility not only of partial dislocation or dislocation, but also of SCFE in adolescents with an adiposogenital phenotype and/or risk factors must be taken into consideration, so that they can be diagnosed as quickly as possible. As a final observation to keep in mind, we propose that SCFE should be considered as part of the pathology in $\mathrm{CP}$ and included in the hip screening surveillance of CP patients older than 10 years of age, particularly in obese and/or adiposogenital phenotype patients with limited capacity for verbal communication.

\section{REFERENCES}

1. WeInER D. Pathogenesis of slipped capital femoral epiphysis: current concepts. J Pediatr Orthop 1996; 5: 67-73. https://doi. org/10.1097/01202412-199605020-00002 
2. Chung CH, Ko KR, KIm JH, ShIm JS. Clinical and radiographic characteristics of atypical slipped capital femoral epiphysis. J Pediatr Orthop 2019; 39: e742-e749. https://doi. org/10.1097/bpo.0000000000001339

3. Kardashian G, Strongwater AM. Slipped capital femoral epiphysis in a cerebral palsy patient: a case report. J Pediatr Orthop B 2010; 19: 428-430. https://doi.org/10.1097/ bpb.0b013e32833af50a

4. Quick TJ, Williamson DM. A case of slipped upper femoral epiphysis in a nonambulant patient with cerebral palsy. J Pediatr Orthop B 2011; 20: 270-271. https://doi.org/10.1097/ bpb.0b013e328344e78c

5. Nhamoucha Y, Tazi M, Abdellaoui $\mathrm{H}$, Alaoui O, Andaloussi S, Oukhoya $M$ et al. Slipped capital femoral epiphysis in a patient with cerebral palsy due to seizure. Pan Afr Med J 2018; 31: 89. https://doi.org/10.11604/ pamj.2018.31.89.6832

6. HERring JA. Tachdjian's Pediatric Orthopaedics. 4th ed. Philadelphia: Saunders/Elsevier, 2008.

7. Gelberman RH, Cohen MS, Shaw BA, Kasser JR, GRIFFIn PP, WILKINSON RH. The association of femoral retroversion with slipped capital femoral epiphysis. J Bone Joint Surg Am 1986; 68: 1000-1007. https://doi.org/10.2106/00004623198668070-00006

8. Pritchett JW, Perdue KD. Mechanical factors in slipped capital femoral epiphysis. J Pediatr Orthop 1988; 8: 385-388. https://doi. org/10.1097/01241398-198807000-00001

9. Miller F, Slomczykowski M, Cope R, Lipton G. Computer modelling of the pathomechanics of spastic hip dislocation in children. J Pediatr Orthop 1999; 19: 486-492. https://doi. org/10.1097/00004694-199907000-00012

10. Duncan JW, LowELl WW. Anterior slip of the capital femoral epiphysis. Report of a case and discussion. Clin Orthop Relat Res 1975; 110: 171-173. https://doi.org/10.1097/00003086197507000-00022

11. Mirkopoulos N, Weiner DS, Askew M. The evolving slope of the proximal femoral growth plate relationship to slipped capital femoral epiphysis. J Pediatr Orthop 1988; 87: 268-273. https://doi.org/10.1097/01241398-19880500000003

12. Fishrin Z, Armstrong DG, Shah H, Patra A, MiHALKO WM. Proximal femoral physis shear in slipped capital femoral epiphysis-a finite element study. J Pediatr Orthop 2006: 26: 291-294. https://doi.org/10.1097/01. bpo.0000217730.39288.09

13. Milus MB, Novais EN. In situ fixation for slipped capital femoral epiphysis. Perspectives in 2011. J Bone Joint Surg 2011; 93: 46-51. https://doi.org/10.2106/jbjs.k.00040

14. Topoleski TA, Kurtz CA, Grogan DP. Radiographic abnormalities and clinical symptoms associated with patella alta in ambulatory children with cerebral palsy. J Pediatr Orthop 2000; 20: 636-639. https://doi. org/10.1097/01241398-200009000-00016

15. Schur MV, Andras LM, Broom AM, Barrett KK, Bowman CA, Luther $\mathrm{H}$ et al. Continuing delay in the diagnosis of slipped capital femoral epiphysis. J Pediatr 2016; 177: 250-254. doi: 10.1016/j.jpeds.2016.06.029. https://doi. org/10.1016/j.jpeds.2016.06.029 